\title{
Lower Lobe of the Right Lung
}

National Cancer Institute

\section{Source}

National Cancer Institute. Lower Lobe of the Right Lung. NCI Thesaurus. Code C33022.

The lobe of the right lung situated below the oblique fissure. 